\title{
Individual Differences in Cyclosporine A Pharmacokinetics and Its Association with Acute Renal Function Following Heart Transplantation
}

\author{
Pål Falck ${ }^{1}$, Arnt E. Fiane ${ }^{2}$, Odd R. Geiran ${ }^{2,3}$ and Anders Åsberg ${ }^{1, *}$ \\ ${ }^{I}$ Department of Pharmaceutical Biosciences, School of Pharmacy, University of Oslo; ${ }^{2}$ Department of Thoracic and \\ Cardiovascular Surgery, Rikshospitalet Medical Center, Oslo, Norway and ${ }^{3}$ Facultydivision Rikshospitalet, University \\ of Oslo, Oslo Norway
}

\begin{abstract}
Background: The secondary metabolites of cyclosporine A (CsA), AM19, AM1c and AM1c9, have been indicated to be nephrotoxic. The aim of the present pilot study was to investigate the relationship between acute renal failure and CsA metabolite levels, including relevant pharmacokinetic genotypes, following heart transplantation.

Methods: Whole-blood samples were drawn the first posttransplant week in 22 patients (median 54 years, range from 27 to 65). Whole blood concentrations of CsA and its six main metabolites were analyzed with a validated HPLC-MS/MS method, and relevant $C Y P 3 A 5$ and $A B C B 1$ genotypes determined. Renal function was monitored daily during the first posttransplant month and also at months 3,6 and 12 .

Results: One patient died early posttransplant. Six patients were in need of dialysis directly after transplantation. Nine patients developed sustained impaired renal function, while six had stable renal function. Sustained renal impairment tended to be associated with high levels of toxic metabolites $(\mathrm{P}=0.08)$. Six of the patients with possible $A B C B 1$ TTT-haplotype developed renal impairment $(\mathrm{P}=0.12)$.

Conclusion: The present study indicates that toxic CsA metabolites seems to be associated with development of impaired renal function and together with $A B C B 1$ genotyping they might be promising biomarkers for optimalization of immunosuppressive drug treatment in future studies.
\end{abstract}

Key Words: Cyclosporine A, heart transplantation, renal impairment, metabolites, nephrotoxicity.

\section{INTRODUCTION}

Renal failure following heart transplantation is a frequent complication and associated with impaired survival [1]. There are several risk factors but most of them are nonmodifiable [2-6]. Cyclosporine A (CsA) has a narrow therapeutic window and induce reduced renal function following each dose [7, 8]. The mechanisms of renal impairment following heart transplantation are not fully elucidated, but CsA is often mentioned as a risk factor [9-11]. Several clinical trials have shown encouraging results by lowering CsA concentrations [12].

CsA undergoes extensive metabolism, primarily via CYP3A, to over 30 metabolites [13-15] and shows high variation $[15,16]$. The general understanding is that CsA metabolites are less toxic than the parent drug [17-19]. However, secondary metabolites, AM19, AM1c and AM1c9, may be associated with nephrotoxicity [17, 20-24]. In vitro studies indicate that CYP3A5 expressers produce more AM19 and AM1c9 metabolites [15], and they directly affect renal haemodynamics. In addition is AM1 and AM9 cytotoxic [17, 25].

\footnotetext{
*Address correspondence to this author at the Department of Pharmaceutical Biosciences, School of Pharmacy, University of Oslo, P.O. Box. 1068, Blindern, 0316 Oslo, Norway; Tel: +47 228565 59; Fax: +47 228544 02; E-mail: anders.asberg@farmasi.uio.no
}

P-glycoprotein (P-gp) is an efflux transporter coded by the $A B C B 1$ gene that affects CsA pharmacokinetics [26, 27]. The TTT-haplotype of C1236T, G2677T and C3435T SNP's has been suggested to have impaired activity [28], which may attenuate the efflux of compounds out of kidney cells and therefore be a risk factor for nephrotoxicity.

In the present pilot study in heart transplant recipients the association between CsA metabolite levels, and acute renal impairment were studied. Renal function was followed for one year and the effects of different genotypes were in addition examined.

\section{MATERIAL AND METHODOLOGY}

\section{Patients}

Twenty-two heart transplant recipients (11 men), median age of 54 years (range from 27 to 65 years), were enrolled consecutively in this single centre, pilot study. The patients received CsA, mycophenolate mofetil (MMF) and steroids as immunosuppressive therapy. Treatment was initiated with $100 \mathrm{mg}$ CsA intravenously at transplantation, followed by oral twice daily dosing. C0 first month; 250 to $300 \mu \mathrm{g} / \mathrm{L}$ and then tapered to between 60 to $120 \mu \mathrm{g} / \mathrm{L}$ during the one year follow-up. All patients received $1.5 \mathrm{~g}$ twice daily $\mathrm{MMF}$ and steroids in accordance to the following protocol; intravenous methylprednisolone $(500 \mathrm{mg})$ at the time of transplantation 
and three more doses $(125 \mathrm{mg})$ followed by oral prednisolone $(0.2 \mathrm{mg} / \mathrm{kg})$ twice daily from the second day with tapering after two weeks. Basiliximab induction (first dose of 20 $\mathrm{mg}$ intravenous within 2 hours pretransplant and a second dose of $20 \mathrm{mg}$ intravenous on the fourth posttransplant day) was used in two patients. Demographic baseline data are shown in Table 1. The study was performed in accordance with the Declaration of Helsinki and all patients signed a written informed consent. The study was evaluated by the Regional Ethics Committee of Health Region South in Norway.

\section{Study Design}

Renal function was monitored daily (plasma creatinine) during the first posttransplant month and also at months 3,6 and 12. Patients were divided in three groups based on renal function pattern during the first posttransplant month. Group A: patients with no, or only modest increase in plasma creatinine (i.e. < 30\% increase from pretransplant level), group B: patients with sustained increase in plasma creatinine of $>30 \%$ from pretransplant levels but not in need of dialysis and group C: patients in need of dialysis after transplantation.
A blood sample was drawn during the first posttransplant week (median 4 days, range from 1 to 5 ) for the analysis of CsA and its six main metabolites as well as CYP3A5 (*3) and $A B C B 1$ (G1199A, C1236T, G2677A/T, C3435T) genotypes. Blood sampling was performed at a median 2.5 hours (range from 1 to 25) following CsA administration.

\section{Cyclosporine Analyses}

Whole blood CsA and metabolite concentrations were analyzed with a validated HPLC-MS/MS method [29]. In brief, after protein precipitation with methanol and centrifugation, the supernatants were subjected to solid phase extraction using Oasis ${ }^{\circledR}$ HLB cartridges. CsA and the six metabolites AM19, AM1c9, AM1, AM9, AM1c, AM4N were all separated chromatographically before MS/MS detection. The method has a linear range of $2.5-3000 \mathrm{ng} / \mathrm{mL}$ for all analytes. Metabolite concentrations were expressed as a percent of CsA levels.

\section{Genotyping}

Genotyping was performed with previously reported polymerase chain reaction-restriction fragment length poly-

Table 1. Demographic Data at Time of Sampling (Mean \pm SD)

\begin{tabular}{|c|c|c|c|c|c|}
\hline & $\begin{array}{c}\text { Group A } \\
\mathrm{N}=6\end{array}$ & $\begin{array}{c}\text { Group B } \\
\mathbf{N}=9\end{array}$ & $\begin{array}{c}\text { Group C } \\
\mathbf{N}=6\end{array}$ & $\begin{array}{c}\text { All } \\
\mathbf{N}=\mathbf{2 1}\end{array}$ & P-Value \\
\hline Age (years) & $49 \pm 13$ & $51 \pm 16$ & $51 \pm 13$ & $50 \pm 14$ & 0.73 \\
\hline Gender $(\mathbf{M} / \mathbf{F})$ & $5 / 1$ & $2 / 7$ & $4 / 2$ & $11 / 10$ & 0.048 \\
\hline Body weight $(\mathrm{kg})$ & $90 \pm 24$ & $72 \pm 15$ & $70 \pm 16$ & $77 \pm 19$ & 0.11 \\
\hline P-creatinine preTx. (mmol/L) & $114 \pm 29$ & $82 \pm 28$ & $107 \pm 34$ & $97 \pm 30$ & 0.13 \\
\hline $\operatorname{ASAT}(\mathbf{U} / \mathbf{L})$ & $74 \pm 53$ & $71 \pm 53$ & $631 \pm 1360$ & $232 \pm 729$ & 0.66 \\
\hline $\operatorname{ALAT}(\mathbf{U} / \mathbf{L}$ & $41 \pm 19$ & $41 \pm 24$ & $631 \pm 1451$ & $209 \pm 776$ & 0.98 \\
\hline GGT (U/L) & $80 \pm 55$ & $77 \pm 44$ & $131 \pm 197$ & $93 \pm 109$ & 0.83 \\
\hline CsA dose $(\mathrm{mg} / \mathrm{day})^{*}$ & $425 \pm 95$ & $303 \pm 63$ & $321 \pm 99$ & $343 \pm 96$ & 0.054 \\
\hline CsA dose (mg/kg/day) & $4.9 \pm 1.0$ & $4.3 \pm 0.9$ & $4.6 \pm 1.0$ & $4.5 \pm 0.9$ & 0.73 \\
\hline $\operatorname{CsA} \mathrm{C} 2 \operatorname{conc}(\mu \mathrm{g} / \mathrm{L})^{* * *}$ & $1061 \pm 593$ & $1058 \pm 656$ & $1352 \pm 875$ & $1143 \pm 686$ & 0.72 \\
\hline Days since $\mathbf{T x}$. & $3.7 \pm 1.4$ & $3.0 \pm 1.3$ & $3.7 \pm 0.8$ & $3.4 \pm 1.2$ & 0.50 \\
\hline Sampling time (hour) & $2.5 \pm 0.8$ & $3.0 \pm 0.7$ & $7.9 \pm 9.8$ & $4.3 \pm 5.6$ & 0.38 \\
\hline CYP $3 A 5 * 1$ genotype & $1 / 6$ & $2 / 9$ & $2 / 6^{* *}$ & $5 / 21$ & 0.56 \\
\hline Possible $A B C B 1$ TTT-haplotype & $3 / 6$ & $6 / 9$ & $1 / 6$ & $10 / 21$ & 0.16 \\
\hline
\end{tabular}

Abbreviations: P-creatinine: plasma creatinine, ASAT: aspartate aminotransferase, ALAT: alanine aminotransferase, GGT: $\gamma$-glutamyl transferase, Tx: transplantation, SBP: systolic blood pressure, DBP: diastolic blood pressure. Group A: unchanged renal function; Group B: sustained renal dysfunction; Group C: patients in need of dialysis from the day of transplantation.

*Five patients received their dose intravenously. The value given is the normalized oral dose (IV dose * 3).

** One of these patients were homozygote CYP $3 A 5^{*} 1 / * 1$.

***C2: estimated concentration 2 hours postdose.

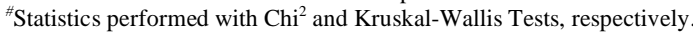


morphism assays on deoxyribonucleic acid (DNA), extracted from EDTA blood by QIAamp (Qiagen, Valencia, Calif), using specific primers and separation on 3\% agarose gels [30-32]. All patients were screened for relevant polymorphisms in CYP3A5 (*2 [C27289A, Thr398Asn] and *3 (A6986G, splicing defect]) and $A B C B 1$ (G1199A, C1236T, G2677A/T, and C3435T). Positive controls were kindly supplied by Dr D. Katz, Abbott Laboratories, Abbott Park, Il $(A B C B 1)$, and Dr R. van Schaik, Department of Clinical Chemistry, Erasmus MC, The Netherlands (CYP3A5).

\section{Statistical Analyses}

The statistical analyses were performed using $\mathrm{Chi}^{2} /$ Mann-Whitney U Test/unpaired student $t$-test and KruskalWallis Test with P-values $<0.05$ considered as significant. All statistical analyses were performed using SPSS version 14.0 .

\section{RESULTS}

\section{Patients}

The patients included in this study were representative of the over all heart transplant population at our centre. One patient died six days following transplantation due to severe acute rejection, and was excluded from further analyses.

Baseline demographic parameters and relevant $C Y P 3 A 5$ and $A B C B 1$ genotypes were not relevantly different between groups, with the exception of gender (Table 1), with more females in group B developing renal impairment $(\mathrm{P}=0.048)$. Four patients in group $\mathrm{C}$ and one patient in group $\mathrm{A}$ were treated with intravenous $\mathrm{CsA}$ at the time of sampling.

\section{Renal Function}

Six patients needed dialysis from the day of transplantation (group C). Six patients had stable renal function throughout the follow-up period (group A) while nine patients developed sustained renal impairment (group B). One of the patients in group B needed dialysis 15 days following transplantation and one died after 33 days. One patient in group $\mathrm{C}$ died after month 3 , resulting in an overall patient survival of $86.4 \%$. Six patients had mechanical circulatory support at transplantation. Seven patients experienced CMV infection and four patients received treatment for acute rejection episodes (three steroid resistant). One of the six patients in group A developed impaired renal function by one year. The renal function improved over the year to near pretransplant levels in four of the nine patients in group B and patients on dialysis were later able to stop renal replacement therapy.

\section{Cyclosporine A}

Weight adjusted CsA doses and whole blood concentrations were not significantly different between group A and B $(P=0.28$, and $P=0.99$, Table 1$)$, neither were any of the six metabolites measured (Table 2, and Fig. 1). Patients with impaired renal function (group B) showed a tendency of



Fig. (1). The level of metabolites expressed as percent of cyclosporine A for the three study groups: Group A: Stable renal function, Group B: impaired renal function and group $\mathbf{C}$ : patients requiring dialysis. P-value: unpaired t-test between group $\mathbf{A}$ and group B.

Table 2. Mean $( \pm$ SD) CsA and Metabolite Levels $(\mu \mathrm{g} / \mathrm{L})$ in the Different Groups

\begin{tabular}{|c|c|c|c|c|}
\hline & $\begin{array}{c}\text { Group A } \\
\text { N=6 }\end{array}$ & $\begin{array}{c}\text { Group B } \\
\text { N=9 }\end{array}$ & $\begin{array}{c}\text { Group C } \\
\text { N=6 }\end{array}$ & P-Value \\
\hline \hline CsA & $620 \pm 261$ & $471 \pm 290$ & $113 \pm 50.5$ & 0.80 \\
\hline AM19 & $102.6 \pm 75.0$ & $180.0 \pm 151.1$ & $153 \pm 219.6$ & 0.27 \\
\hline AM1c & $116.6 \pm 68.8$ & $136.3 \pm 71.2$ & $26 \pm 11.6$ & 0.61 \\
\hline AM1c9 & $25.2 \pm 15.2$ & $33.1 \pm 17.2$ & $640 \pm 578.4$ & 0.31 \\
\hline AM1 & $517.8 \pm 265.7$ & $753 \pm 495$ & $113 \pm 113.1$ & 0.38 \\
\hline AM9 & $153.8 \pm 78.8$ & $206.8 \pm 124.8$ & $20 \pm 20.5$ & 0.23 \\
\hline AM4N & $49.6 \pm 32.7$ & $34.2 \pm 14.3$ & \\
\hline
\end{tabular}

P-value: unpaired t-test between group A and group B. 
Table 3. CYP3A5 and $A B C B 1$ Genotype Allelic Frequencies in the Different Groups

\begin{tabular}{|c|c|c|c|c|}
\hline SNP & $\begin{array}{c}\text { Group A } \\
\mathbf{N = 6}\end{array}$ & $\begin{array}{c}\text { Group B } \\
\mathbf{N = 9}\end{array}$ & $\begin{array}{c}\text { Group C } \\
\mathbf{N = 6}\end{array}$ \\
\hline N=21 \\
\hline \hline CYP3A5*3 & 0.75 & 0.89 & 0.92 & 0.86 \\
\hline$A B C B 1$ 1199A & 0.00 & 0.00 & 0.00 & 0.00 \\
\hline$A B C B 1$ 1236T & 0.33 & 0.67 & 0.33 & 0.17 \\
\hline$A B C B 13435 \mathrm{~T}$ & 0.17 & 0.39 & 0.50 & 0.62 \\
\hline
\end{tabular}

higher metabolite formation ( $\mathrm{P}>0.08)$. Metabolite AM19 showed the greatest difference and were $164 \%$ higher than in group A $(\mathrm{P}=0.14)$. The three patients with highest relative concentrations of secondary metabolites were all in group B. The patients in need of dialysis (group C) tended to have higher metabolite concentrations compared to group $\mathrm{A}(\mathrm{P}>$ $0.16)$.

\section{CYP3A5 and $A B C B 1$ Genotypes}

No significant differences in $C Y P 3 A 5$ or $A B C B 1$ genotype frequencies were present in this material (Table 3 ). Two of the five patients expressing functional CYP3A5 enzymes $(C Y P 3 A 5 * 1)$ developed sustained renal impairment while one of the five patients showed stable renal function during the study period. With regards to P-gp functionality; six of the ten patients that expressed genotypes previously linked with impaired function ( $A B C B 1$ TTT-haplotypes) developed renal impairment, while three of the ten patients showed stable renal function. Patients with TTT-haplotype and renal impairment had lower AM19 and AM1c9 levels compared to non-TTT-haplotype patients with renal impairment, 37.7 $\pm 38.0 \%$ vs $81.4 \pm 46.7 \%(\mathrm{P}<0.16)$ and $6.7 \pm 3.9 \%$ vs 14.9 $\pm 9.5 \%$ ( $\mathrm{P}<0.08)$, respectively. No significant difference in metabolite formation was observed with regards to functional expression of CYP3A5, with exception of AM9 formation.

\section{DISCUSSION}

Recent trends in immunosuppressive treatment have been either to reduce or replace CsA. Previous studies have shown that secondary CsA metabolites (AM19, AM1c9 and AM1c) may be associated with renal impairment following transplantation [24]. An inverse correlation between renal function and AM19 levels has also been presented [33]. The present study also indicates an association between acute renal impairment following transplantation and CsA metabolic pattern. The question whether the increased formation of nephrotoxic metabolites is a result of impaired renal function or the reason for the nephrotoxicity can not be elucidated by the present study. Increased level of metabolites in dialysis patients indicates that these metabolites at least partly are affected by renal impairment. However, in vitro studies report that the metabolite AM19 and AM1c9 also may be responsible for nephrotoxicity [17] and that CYP3A5 produce more AM19 and AM1c9 [15]. The present study could however neither confirm nor reject this hypothesis, as only three of the fifteen non-dialysis patients expressed CYP3A5. The patient material was also too small to draw any conclusions regarding $A B C B 1$ genotypes. However, six of the nine patients experiencing renal failure were TTT-haplotypes $(\mathrm{P}=$ 0.12 ), as compared to the previously reported frequency of approximately 0.4 [34]. In addition, the six patients with TTT-haplotype in group B all showed lower exposure of metabolites AM1 and AM1c9 (46.3\% and 45.0\%) compared to non-TTT-haplotypes. This indicates that impaired P-gp activity may induce higher sensitivity to CsA toxicity since intrarenal exposure may be higher. However, all four of the patients with acute rejections had also TTT-haplotype opposing the hypothesis of increased intracellular concentrations in these patients [35].

The major limitation of the study is the small samplesize, but also the facts that blood samples were drawn at different times following last dose of CsA and that some patients received intravenous $\mathrm{CsA}$ introduces additional limitation.

\section{CONCLUSION}

The present pilot study indicates that heart transplant recipients who experience reduced renal function early posttransplant have an altered metabolic pattern of CsA. The primary metabolites AM1 and AM9 and their secondary metabolites AM19, AM1c9 and AM1c tended to be higher in patients with impaired renal function compared to patients with stable renal function. This study also indicates that reduced P-gp activity may augment CsA nephrotoxicity. Both CsA metabolic pattern and $A B C B 1$ genotyping deserve further investigations to explore their potential as biomarkers for CsA induced nephrotoxicity.

\section{TRIAL REGISTRATION} $355)$

The trial is registered on ClinicalTrials.gov (NCT00264-

\section{ACKOWLEDGEMENTS}

Beata Mohebi is acknowledged for the analytical work performed, and we would also like to thank all participating patients for giving their consent and donating blood samples.

\section{REFERENCES}

[1] Ojo AO, Held PJ, Port FK, et al. Chronic renal failure after transplantation of a nonrenal organ. N Engl J Med 2003; 349: 931-40. 
[2] Vossler MR, Ni H, Toy W, Hershberger RE. Pre-operative renal function predicts development of chronic renal insufficiency after orthotopic heart transplantation. J Heart Lung Transplant 2002; 21: 874-81.

[3] Garrido IP, Crespo-Leiro MG, Paniagua MJ, et al. Independent predictors of renal dysfunction after heart transplantation in patients with normal pretransplant renal function. J Heart Lung Transplant 2005; 24: 1226-30.

[4] Abraham KA, McGorrian C, O'Kelly P, et al. The effect of preexisting ischaemic heart disease on renal dysfunction in cardiac transplant recipients. Am J Transplant 2002; 2: 355-9.

[5] Ishani A, Erturk S, Hertz MI, Matas AJ, Savik K, Rosenberg ME. Predictors of renal function following lung or heart-lung transplantation. Kidney Int 2002; 61: 2228-34.

[6] Al Aly Z, Abbas S, Moore E, Diallo O, Hauptman PJ, Bastani B. The natural history of renal function following orthotopic heart transplant. Clin Transplant 2005; 19: 683-9.

[7] Asberg A, Christensen H, Hartmann A, Berg KJ. Diltiazem modulates cyclosporin A induced renal hemodynamic effects but not its effect on plasma endothelin-1. Clin Transplant 1998; 12: 363-70.

[8] Nankivell BJ, Borrows RJ, Fung CL, O'Connell PJ, Allen RD, Chapman JR. The natural history of chronic allograft nephropathy. N Engl J Med 2003; 349: 2326-33.

[9] Herlitz H, Lindelow B. Renal failure following cardiac transplantation. Nephrol Dial Transplant 2000; 15: 311-4.

[10] Hornung TS, de Goede CG, O'Brien C, Moghal NE, Dark JH, O'Sullivan F. Renal function after pediatric cardiac transplantation: the effect of early cyclosporin dosage. Pediatrics 2001; 107: 134650 .

[11] Wilkinson AH, Cohen DJ. Renal failure in the recipients of nonrenal solid organ transplants. J Am Soc Nephrol 1999; 10: 1136-44.

[12] Salvadori M, Rosati A, Bertoni E, et al. Low 1-year cyclosporine microemulsion doses are associated with better 5-year renal graft function: an insight from MOST, a multinational observational study. Transplant Proc 2006; 38: 1010-3.

[13] Sattler M, Guengerich FP, Yun CH, Christians U, Sewing KF. Cytochrome P-450 3A enzymes are responsible for biotransformation of FK506 and rapamycin in man and rat. Drug Metab Dispos 1992; 20: 753-61.

[14] Christians U, Sewing KF. Cyclosporin metabolism in transplant patients. Pharmacol Ther 1993; 57: 291-345.

[15] Dai Y, Iwanaga K, Lin YS, et al. In vitro metabolism of cyclosporine A by human kidney CYP3A5. Biochem Pharmacol 2004; 68: 1889-902.

[16] Bertz RJ, Granneman GR. Use of in vitro and in vivo data to estimate the likelihood of metabolic pharmacokinetic interactions. Clin Pharmacokinet 1997; 32: 210-58.

[17] Copeland KR, Yatscoff RW. Comparison of the effects of cyclosporine and its metabolites on the release of prostacyclin and endothelin from mesangial cells. Transplantation 1992; 53: 640-5.

[18] Bowers LD. Studies of cyclosporine and metabolite toxicity in renal and hepatocyte culture systems. Transplant Proc 1990; 22: 1135-6.

[19] Copeland KR, Thliveris JA, Yatscoff RW. Toxicity of cyclosporine metabolites. Ther Drug Monit 1990; 12: 525-32.

[20] Christians U, Kohlhaw K, Budniak J, et al. Ciclosporin metabolite pattern in blood and urine of liver graft recipients. I. Association of ciclosporin metabolites with nephrotoxicity. Eur J Clin Pharmacol 1991; 41: 285-90.
[21] Rosano TG, Pell MA, Freed BM, Dybas MT, Lempert N. Cyclosporine and metabolites in blood from renal allograft recipients with nephrotoxicity, rejection, or good renal function: comparative high-performance liquid chromatography and monoclonal radioimmunoassay studies. Transplant Proc 1988; 20: 330-8.

[22] Kohlhaw K, Wonigeit K, Schafer O, Ringe B, Bunzendahl H, Pichlmayr R. Association of very high blood levels of cyclosporin metabolites with clinical complications after liver transplantation. Transplant Proc 1989; 21: 2232-3.

[23] Wonigeit K, Kohlhaw K, Winkler M, Schaefer O, Pichlmayr R. Cyclosporine monitoring in liver allograft recipients: two distinct patterns of blood level derangement associated with nephrotoxicity. Transplant Proc 1990; 22: 1305-11.

[24] Kempkes-Koch M, Fobker M, Erren M, et al. Cyclosporine A metabolite AM19 as a potential biomarker in urine for CSA nephropathy. Transplant Proc 2001; 33: 2167-9.

[25] Cole E, Skorecki K, Cheung F, Wong PY, Fung LS, Levy GA. Cyclosporine A in contrast to a cyclosporine metabolite (OL-17) specifically inhibits growth of renal cells in culture. Transplant Proc 1988; 20: 732-7.

[26] Thiebaut F, Tsuruo T, Hamada H, Gottesman MM, Pastan I, Willingham MC. Cellular localization of the multidrug-resistance gene product P-glycoprotein in normal human tissues. Proc Natl Acad Sci USA 1987; 84: 7735-8.

[27] Lown KS, Mayo RR, Leichtman AB, et al. Role of intestinal Pglycoprotein (mdr1) in interpatient variation in the oral bioavailability of cyclosporine. Clin Pharmacol Ther 1997; 62: 248-60.

[28] Burckart GJ, Liu XI. Pharmacogenetics in transplant patients: can it predict pharmacokinetics and pharmacodynamics? Ther Drug Monit 2006; 28: 23-30.

[29] Falck P, Guldseth H, Åsberg A, Midtvedt K, Reubsaet JL. Determination of ciclosporin A and its six main metabolites in isolated T-lymphocytes and whole blood using liquid chromatographytandem mass spectrometry. J Chromatogr B Analyt Technol Biomed Life Sci 2007; 3: 3.

[30] Falck P, Guldseth H, Asberg A, Midtvedt K, Reubsaet JL. Determination of ciclosporin A and its six main metabolites in isolated T-lymphocytes and whole blood using liquid chromatographytandem mass spectrometry. J Chromatogr B 2007; 852: 345-52.

[31] Katz DA, Grimm DR, Cassar SC, et al. CYP3A5 genotype has a dose-dependent effect on ABT-773 plasma levels. Clin Pharmacol Ther 2004; 75: 516-28.

[32] van Schaik RH, van der Heiden IP, van den Anker JN, Lindemans J. CYP3A5 variant allele frequencies in Dutch Caucasians. Clin Chem 2002; 48: 1668-71.

[33] Falck P, Vethe NT, Asberg A, et al. Cinacalcet's effect on the pharmacokinetics of tacrolimus, cyclosporine and mycophenolate in renal transplant recipients. Nephrol Dial Transplant 2008; 23: 1048-53.

[34] Marzolini C, Paus E, Buclin T, Kim RB. Polymorphisms in human MDR1 (P-glycoprotein): recent advances and clinical relevance. Clin Pharmacol Ther 2004; 75: 13-33.

[35] Falck P, Asberg A, Guldseth $\mathrm{H}$, et al. Declining intracellular Tlymphocyte concentration of cyclosporine a precedes acute rejection in kidney transplant recipients. Transplantation 2008; 85: 17984 .

(C) Falck et al.; Licensee Bentham Open.

This is an open access article licensed under the terms of the Creative Commons Attribution Non-Commercial License (http: //creativecommons.org/licenses/ by-nc/3.0/) which permits unrestricted, non-commercial use, distribution and reproduction in any medium, provided the work is properly cited. 